\title{
Nurses' Performance Regarding Postoprative Discomfort among Patients Undergoing Abdominal Wall Hernia Repair
}

\author{
${ }^{1}$ Dr. Amal Bakr Abo El-Ata; ${ }^{2}$ Dr. Hayat Mohamed, ${ }^{3}$ Sara Abd Elfatah Abas \\ ${ }^{1}$ Assistant professor of medical surgical nursing - Faculty of Nursing Port Said \\ University; ${ }^{2}$ Lecturer of Medical Surgical nursing - Faculty of Nursing - Port Said \\ University; ${ }^{3}$ B.Sc. Nursing, Faculty of Nursing - Mansoura University
}

\begin{abstract}
Background: Effective postoperative discomfort management is an essential component to good quality of care, nursing a patient in discomfort is a challenging task requiring upto-date knowledge, skilled interventions and attitudes that convey trust. Aim: Assess nurses' performance regarding postoperative discomfort among patients undergoing abdominal wall hernia repair. Subjects and Method: a descriptive research design was used. Setting: The study was conducted at the surgical in port said city (El-Zohoor Hospital and Port Said General Hospital)and Damietta. Subjects: A 6o convenient nurses participated in the study Tools: data were collected using three tools, Nurses' Knowledge questionnaire, observational check list for nurses' practice and Nurses' attitude toward postoperative discomfort. Results: the result of study indicated that $71.7 \%$ of the studied nurses had unsatisfactory knowledge, $83.3 \%$ had satisfactory practice, $66.7 \%$ of them had negative attitude Conclusion: most of the studied nurses had unsatisfactory knowledge while majority of them had satisfactory practice and more than two third of studied nurses had negative attitude. Recommendations: there are obvious needs for conducted an in service educational and training programs to improve nurse's knowledge, practice and nurses' attitude regarding postoperative discomfort among patients undergoing abdominal wall hernia repair.
\end{abstract}

Key Words: Abdominal wall hernia, nurses' performance, postoperative discomfort 


\section{INTRODUCTION}

Abdominal wall hernia is a weakness in muscle wall of abdomen through which a part of the bowel or other abdominal structure protrudes. Hernias can also penetrate through any other defect in the abdominal wall, through the diaphragm, or through other structures in the abdominal cavity. Also Hernia is the protrusion of an organ through an abdominal opening in the muscle wall of the cavity that surrounds it. It may be congenital or may be due to the failure of certain structures to close after birth or may acquire later in life by some factors as obesity, muscular weakness, surgery or illness. (Linda et al., 2o13; Iqbal, 2015; Sultan, 2015) .

According study of (Timby\&Simth, 2014 )reported that the most common abdominal hernias are inguinal, umbilical, femoral, and incision, with the most common type is inguinal hernias. Inguinal hernias are more prevalent in men than women. Femoral and umbilical hernias are more frequent in women than men. Lifetime risk for inguinal hernia is around $27 \%$ for men and around $3 \%$ for women. Inguinal hernia repair is one of the most common operations in general surgery.

In addition to the study by (Velanovich, et al., 2015; Fitzgibbons, 2016; Russell, et al., 2017).reported that the prevalence of hernia is dependent on risk factors,include sex, age, cough, constipation repeated pregnancies, obesity, smoking, heavy lifting, prior operations and hereditary factors. There was the incidence of hernia in males higher $(67.27 \%)$ than females $(32.72 \%)$.

Zegerman, Ezri \& Weinbroum (2014) mentioned that, patient experience distress, other than pain, after abdominal wall hernia repair. This postoperative distress may greatly affect the patient's state of well-being. The term "postoperative discomfort" has been used to define a clinical picture that includes signs and symptoms that distress patients who have undergone surgery. Suppression of postoperative distress or discomfort suppression might be considered as a priority of nursing care in the early postoperative period .

The patient in surgical department experiences discomfort after hernia repair surgery, the primary gastrointestinal postoperative discomfort are nausea, vomiting, abdominal distention, hiccups and constipation the most common early postoperative discomfort are 
Nausea and vomiting this may be due to factors include anesthesia, pain, opioid, decreased peristalsis and Resuming oral intake too soon. the nurse have important role to prevent aspiration if the patient vomits while still sleepy from anesthesia, having suction equipment readily available at the bedside and turning the patient to the side line position and other nursing intervention that may be effective biofeedback, hypnosis, relaxation, guided imagery, music therapy, distraction and acupressure. Chintamani (2016), linton (2015) .

Nurses have the maximum contact with patients since they represent as the largest healthcare providers. Therefore, they play a vital role in discomfort management .also Postoperative discomfort relief is a nursing responsibility in addition to postoperative discomfort management includes drug therapy and other methods of management, such as positioning, massage, relaxation techniques, and diversion. Assess the patients comfort level and the effectiveness of the therapies.(Wengström, 2014; Basavanthappa, 2015).

Nurses patients' advocates and should act at all times in such a manner as to promote and safeguard their interests and well-being. this includes ensuring that patients have their discomfort managed appropriately. To assess and relieve discomfort effectively, nurses need to be competent in this area. The World Health Organization (WHO) states that competence requires knowledge, appropriate attitudes and observational, mechanical or intellectual skills, which together account for the ability to deliver a specified professional service . Inaba, Okinaga, \& Fukushima, (2014)

Ferrell \& McCaffery, (2014) Nurses play a vital role in relieving patients' suffering: they work as mediator between the patient and health team members when nurses' lack of knowledge ,practice and attitude regarding postoperative discomfort among patients undergoing abdominal wall hernia repair. these affect on nursing care for patient, poor communication with patient, his familes and health team members also effect on nursing care that provide to patients'. lack of time, staff shortages and increased workload were significant factors contributing to ineffective discomfort management in practice.

Poor management of post-operative discomfort can contribute to medical complications including pneumonia, deep vein thrombosis, infection and delayed healing, as well as the development of chronic pain. It is therefore important that all patients undergoing surgery should receive adequate discomfort management. (Wells, et al., 2015). 


\section{Significance of study:}

Nurse's works in surgical department have no specific training or special preparation prior to working in such specialized area. They may have lack of knowledge, improper practice and negative attitude regarding postoperative discomfort among patients undergoing abdominal wall hernia repair (Lewis, et al., 2016).Therefore, the study may explore nursing performance regarding postoperative discomfort among patient undergoing abdominal wall hernia repair . The management of postoperative discomfort is important in the care of postoperative abdominal hernia surgical patients. Management of postoperative discomfort relievers suffering and leads to earlier mobilization, shortened hospital stay, reduced hospital costs, and increased patient satisfaction (Paice, 2014).

The purpose of the study is to assess nurses 'knowledge ,practice and attitude which may aids to improve successful postoperative discomfort management methods and nursing role in the care of postoperative discomfort among patient undergoing abdominal wall hernia repair .

\section{AIM OF STUDY:}

Assess nurses' performance regarding postoperative discomfort among patients undergoing abdominal wall hernia repair

\section{Research Questions:}

\section{To fulfill the aim of the study, four research questions are formulated.}

1. What is the nurses' knowledge regarding postoperative discomfort among patients undergoing abdominal wall hernia repair?

2. What is the nurses' practice regarding postoperative discomfort among patients undergoing abdominal wall hernia repair?

3. What is the nurses' attitude regarding postoperative discomfort among patients undergoing abdominal wall hernia repair? 
4. What are the factors affecting nursing performance regarding postoperative discomfort among patients undergoing abdominal wall hernia repair?

\section{SUBJECTS AND METHOD:}

\section{Research Design:}

A descriptive study design was used to conduct the study.

\section{Study Setting:}

The study was conducted at the surgical Units in Governmental hospitals in port said city(El-Zohoor Hospital and Port Said General Hospital)and Damietta(Eltakhasosy Hospital and Domiat General Hospital) .

\section{Study Subjects:}

A convenient sample of 60 nurses' who provide direct care for patients with postoperative discomfort undergoing abdominal wall hernia repair in surgical Units in the time of data collection from June (2018) to January (2019). Data were collected three days per week.

\section{Tools for data collection}

Data was collected via three tools.

Tool I: Nurses' knowledge questionnaire :This tool was adapted from AbuElhamd (2015) to assess nurses' knowledge regarding postoperative discomfort among patients undergoing abdominal wall hernia repair, It composed of two parts as the following:-

\section{Part 1: Socio-demographic data:}

It is concerned with socio-demographic data of studied nurses as the following name, age, sex, marital status and level of education and also include work related data of studied nurses as the following, place of work, years of experience and attending training program related to postoperative discomfort among patients undergoing abdominal wall hernia repair.

\section{Part (2): Nurses' Knowledge question:}

This tool was adapted from AbuElhamd (2015). It used to assess nurse's knowledge and was composed of (13) questions related to postoperative discomfort among patients undergoing abdominal wall hernia repair. questions in the form of true and false 
questions including: definition of postoperative discomfort, definition of abdominal wall hernia, causes of abdominal wall hernia, factor help postoperative discomfort in patient undergoing abdominal wall hernia repair such as obesity, wound size and smoking, placed in clean room and its odor, early problem of discomfort that can occur after surgery for patient undergoing abdominal wall hernia repair such as, nausea, vomiting, pain, nurse recommends to the patient after the surgery to repair the abdominal wall hernia if walk or full comfort, eat immediately after the operation, communication between nurse and patient as factors affect the provision of nursing care to the patient. The last question about important of nursing training on the nursing care of the patient who suffers from postoperative discomfort of abdominal wall hernia repair

\section{Scoring system}

Total score for nurse's knowledge questions ranged from (0-13),Zero used for incorrect answer. one used for correct answer

Total nurse's knowledge regarding postoperative discomfort among patients undergoing abdominal wall hernia repair scored as the following:

- $<70 \%$ of total grades was considered unsatisfactory nurse's knowledge about postoperative discomfort $(<9.1$ grades $)$

- $\quad \geq 70 \%$ of total grades was considered satisfactory nurse's knowledge about postoperative discomfort ( $\geq 9.1$ grades)

\section{TooL(II): Nurses' Practiice observational checklist:}

This tool adapted from Abu Elhamed (2015) to assess nurses' actual practice regarding postoperative discomfort among patients undergoing abdominal wall hernia repair; it was composed of (19) questions related to postoperative discomfort among patients undergoing abdominal wall hernia repair and include routine nursing daily care (hand hygiene, personal productive tool, identify the patient, vital signs, oral hygiene, room odors, change bed linens,),

Two question of them contain sub question, the frist question is decrease external stimuli (5 steps) contain, check dressing ,tubes, warms and skin color, provide pharmacologic intervention, emotional support, assess abdomen for distention and firmness and assist diet progression. The second question is breathing exercise(4 steps)contain early 
ambulation, change position frequently, comfortable position and active or passive range of motion exercise.

\section{Scoring system}

For Nurses' observational checklist, score one was given for done while not done was given zero .Total score were 28 grades. The nurse had satisfied practice when the total score equal or above $70 \%$ ( $\geq 19$ grades) and unsatisfied if blow $70 \%$ ( $<19$ grades).

\section{Tool III: Nurses' attitude toward postoperative discomfort:}

This tool developed by Researcher to assess nurses' attitude regarding postoperative discomfort among patients undergoing abdominal wall hernia repair. The attitude scale included a 12 items statement on 5 point Liker scale. The attitude scale included both (10) positive and (2) negative item statements with five response options: strongly agree, agree, to some extent, disagree and strongly disagree. The questioner translated into Arabic language and the retranslation to English to ensure the right meaning of the tool.

\section{Scoring system}

The attitude scale included both positive and negative item statements. Total score is 60 grades, The positive attitude statement were scored as $5=$ strongly agree, $4=$ agree, $3=$ to some extent, 2 = disagree, 1 = strongly disagree, conversely negative attitude statements were scored 1 = strongly agree, $2=$ agree, $3=$ to some extent, $4=$ disagree, $5=$ strongly disagree.

It was considered that

$-\geq 70 \%$ of total grades was considered positive attitude ( $\geq 42$ grades).

$-<70 \%$ of total grades was considered negative attitude (<42 grades).

\section{Pilot study:}

A pilot study was applied to test the applicability of tools, arrangement items, and estimated time needed for each sheet, the researcher randomly select $10 \%$ of study nurses' (6 nurses')within the selected criteria and there were not included in the total sample, the results of the data obtained from the pilot study helped in modification of the tools; items were corrected or added as needed. Accordingly, modifications were done and the final form was developed. 


\section{Field work description:}

The actual field was started during period from the beginning of June (2018) to the end of January (2019) for data collection. The researcher visited the hospital (Port Said city (El-Zohoor Hospital and Port Said General Hospital) and Damietta (Damietta special Hospital and Damietta General Hospital), three days weekly (at morning, afternoon and night) shifts to collect the data by using the previous tools. The purpose of the study was explained by the researcher to nurses who agreed to participate. The researcher identified purpose of the study to the nurses. When nurses agreed, the researcher first meeting all of the study subjects were given the same instruction the researcher met personally with each of them and explaining the purpose of the study. The first phase that was done by the researcher through observation of the studied nurses when do their actual work, the researcher was observing nurses' practical skills regarding postoperative discomfort among patients undergoing abdominal wall hernia repair. The time needed to complete the checklist varies ranged between 25-35 mints. Each nurse was being observed for 2 hours at beginning of each shift for morning shift then she was asked to fulfill the questionnaire. Then giving them the questionnaire sheet to fill it. This took about 20 to 30 minutes from each nurse. Distribution of the questionnaire sheet was done after the end of morning shift for nurses working at morning shift and was given to the afternoon (evening shift) nurses before starting their work and was given to the night nurses before starting their work.

\section{(III) Administrative Design}

A formal letter from the Dean of the Faculty of nursing Port Said University was submitted. The aim of the study and procedures were explained to them to attain their cooperation .An official permission for data collection was obtained from hospital administrators or directors of Port Said city (El-Zohoor Hospital and Port Said General Hospital) and Damietta (Damietta special Hospital and Damietta General Hospital) to conduct the study after explanation of the study aim and process.

\section{Ethical Considerations:}

The agreement for participation of the nurses was taken after aims of the study have been explained to them. A verbal informed consent was obtained from the nurse to ensure willingness to engage in the study after explaining its purpose. They were informed about 
their rights to refuse or withdraw at any time with no consequences on their care. The study interventions could not have any harmful effect on participants and they were assured that the information collected would be treated confidentially and used for the research purpose only.

\section{STATISTICAL DESIGN :}

Data entry and analysis were done using SPSS 17 (statistical packages for social science). Quality control was done at the stages of coding and data entry. Data were presented using descriptive statistics in the form of frequencies and percentages for qualitative variables, and means and standard deviations for quantitative variables as well as inferential statistics. Qualitative variables were compared using $\mathrm{f}$ test, $\mathrm{t}$ test \& $\mathrm{r}$ test. Person correlation test were used to test the relation between the studies variables. For interpretation of results, the $\mathrm{p}$ value $\leq 0.05$ was considered significant level in some tables. Meanwhile, the $\mathrm{p}$ value $\leq 0.001$ was considered highly significant level for other table.

\section{RESULTS:}

Table (1): reveals that $45 \%$ of the studied nurses were in age group from 20 to less than 30 years old while $1.7 \%$ of them were in age group from 5o to6o years old. Majority of studied nurses $93.3 \%$ were female, $65 \%$ of studied nurses graduated from Diploma three years and $83.3 \%$ of the studied nurses were married.

Figure(1): demonstrates $81.7 \%$ of the studied nurses not attending training program regarding post-operative discomfort among patient undergoing abdominal wall hernia repair.

Figure (2): Shows that $71.7 \%$ of the studied nurses had unsatisfactory total knowledge regarding post-operative discomfort among patient undergoing abdominal wall hernia repair.

Figure (3): Shows that $66.7 \%$ of studied nurses had negative attitude and $33.3 \%$ had positive attitude regarding postoperative discomfort among patient undergoing abdominal wall hernia repair. 
Figure (4): Demonstrate that $83.3 \%$ of studied nurses had satisfactory total practice regarding postoperative discomfort among patient undergoing abdominal wall hernia repair

Table(2): demonstrates that, there was not statistically significant relation between total nurses' knowledge and sex, age, level of education \& marital status of studied nurses regarding postoperative discomfort among patient undergoing abdominal wall hernia repair.

Table (3) demonstrates that, there was not statistically significant relation between nurses' practice and sex, age, level of education \& marital status of studied nurses regarding postoperative discomfort among patient undergoing abdominal wall hernia repair.

Table(4): Shows that, relation between total nurses' attitude regarding postoperative discomfort among patients undergoing abdominal wall hernia repair according socio demographic data, demonstrates that, there was not statistically significant relation between total nurses' attitude and sex, age, level of education \& marital status of studied nurses regarding postoperative discomfort among patient undergoing abdominal wall hernia repair.

Table (5): demonstrates that there were negative not statistically significant correlation between total nurses' practice with attitude and knowledge while there was positive statistically correlation between total nurses' attitude and knowledge regarding postoperative discomfort among patients undergoing abdominal wall hernia repair.

Table (1): Socio-demographic data of studied nurses $(n=60)$

\begin{tabular}{|c|c|c|}
\hline Socio-demographic data & No. & $\%$ \\
\hline \multicolumn{3}{|l|}{ Age (years) } \\
\hline $20-<30$ & 27 & 45.0 \\
\hline $30-<40$ & 24 & 40.0 \\
\hline $40-<50$ & 8 & 13.3 \\
\hline $50-60$. & 1 & 1.7 \\
\hline \multicolumn{3}{|l|}{ Sex } \\
\hline Male & 4 & 6.7 \\
\hline
\end{tabular}




\begin{tabular}{||l|c|c||}
$\mid$ Female & 56 & $\mathbf{9 3 . 3}$ \\
\hline Level of education & & \\
Diploma three years & 39 & $\mathbf{6 5 . 0}$ \\
Nursing technician institute & 20 & 33.3 \\
Bachelor of nursing & 0 & 0.0 \\
Bachelor + Postgraduate studies & 1 & 1.7 \\
\hline Marital status & 9 & 15.0 \\
Single & 50 & $\mathbf{8 3 . 3}$ \\
Married & 1 & 1.7 \\
Divorced & &
\end{tabular}

\section{Attendikg training program}

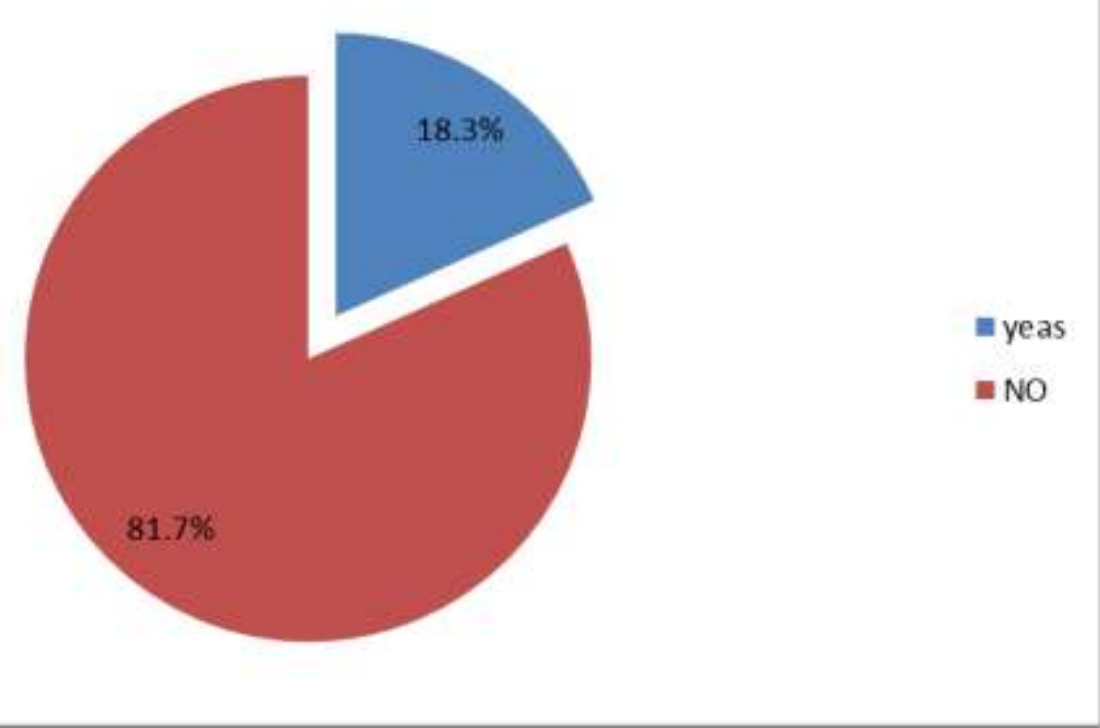

FIGURE (1): Distribution ofnurse's according to attending training program regarding postoperative discomfort among patient undergoing abdominal wall hernia repair 


\section{Total nurse's knowledge}

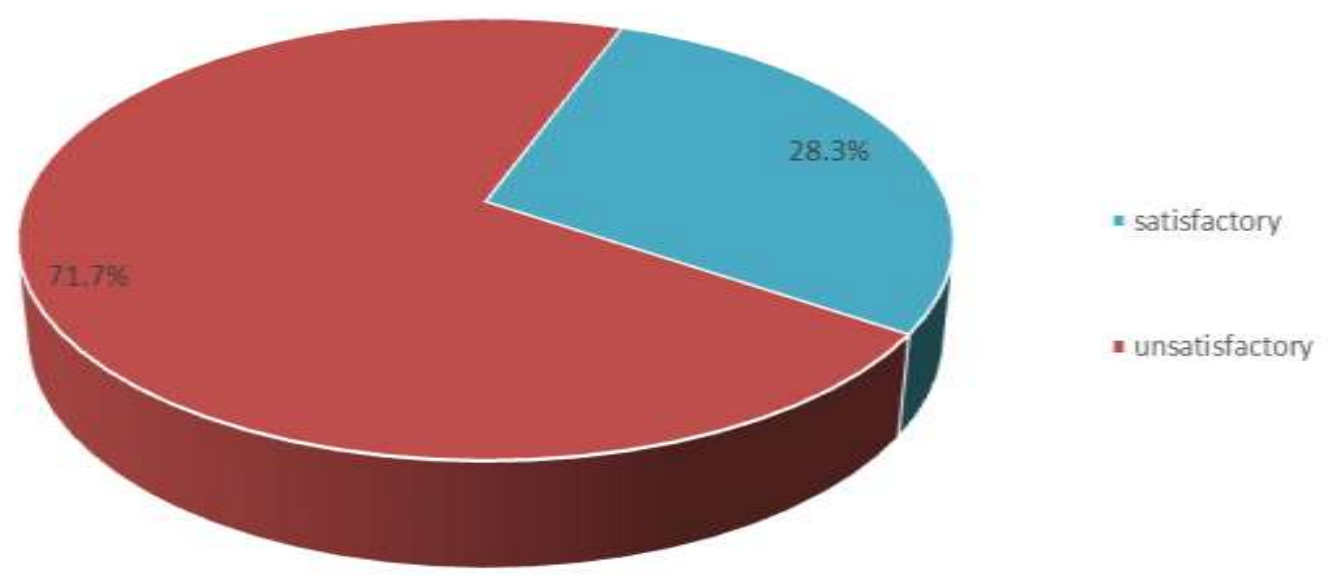

FIGURE (2): total nurse's knowledge regarding postoperative discomfort among patients undergoing abdominal wall hernia repair $(n=60)$.

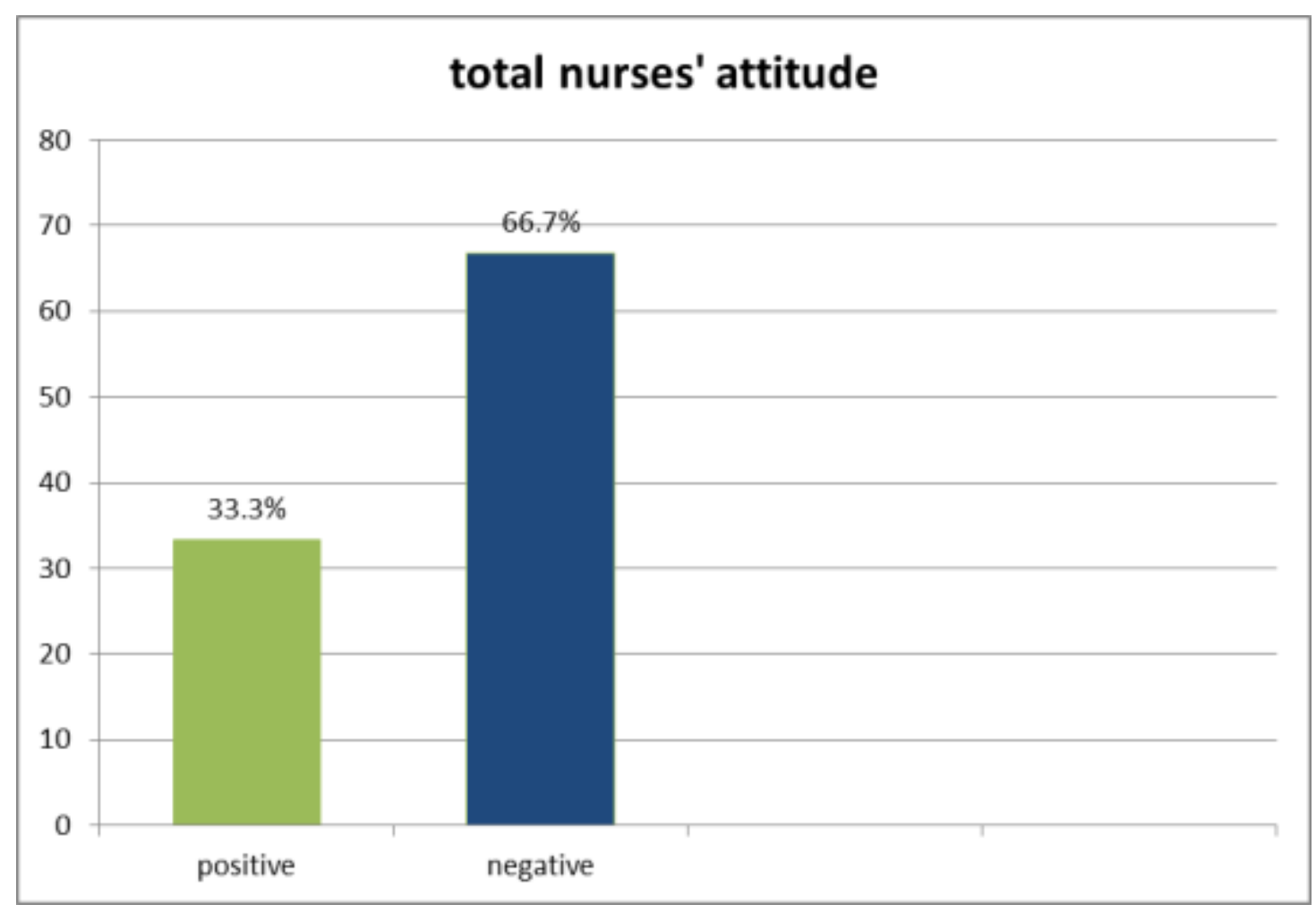


FIGURE (3): total nurses' attitude regarding postoperative discomfort among patients undergoing abdominal wall hernia repair items $(n=60)$.

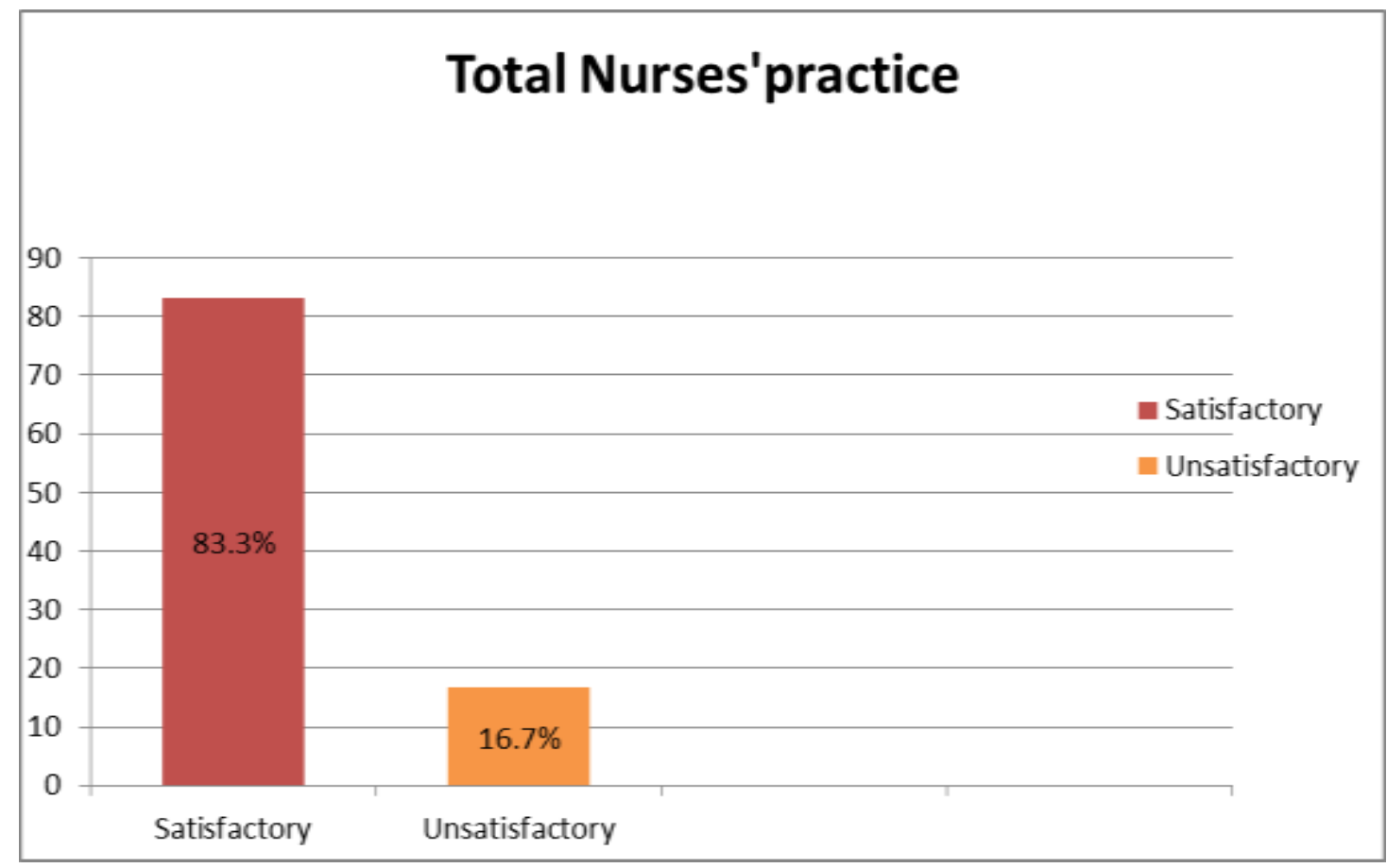

FIGURE (4): Total nurse's practice regarding postoperative discomfort among patient undergoing abdominal wall hernia repair $(n=60)$.

Table (2): Nurses' knowledge regarding postoperative discomfort among patients undergoing abdominal wall hernia repair according to their socio-demographic data $(\mathrm{n}=$ 60)

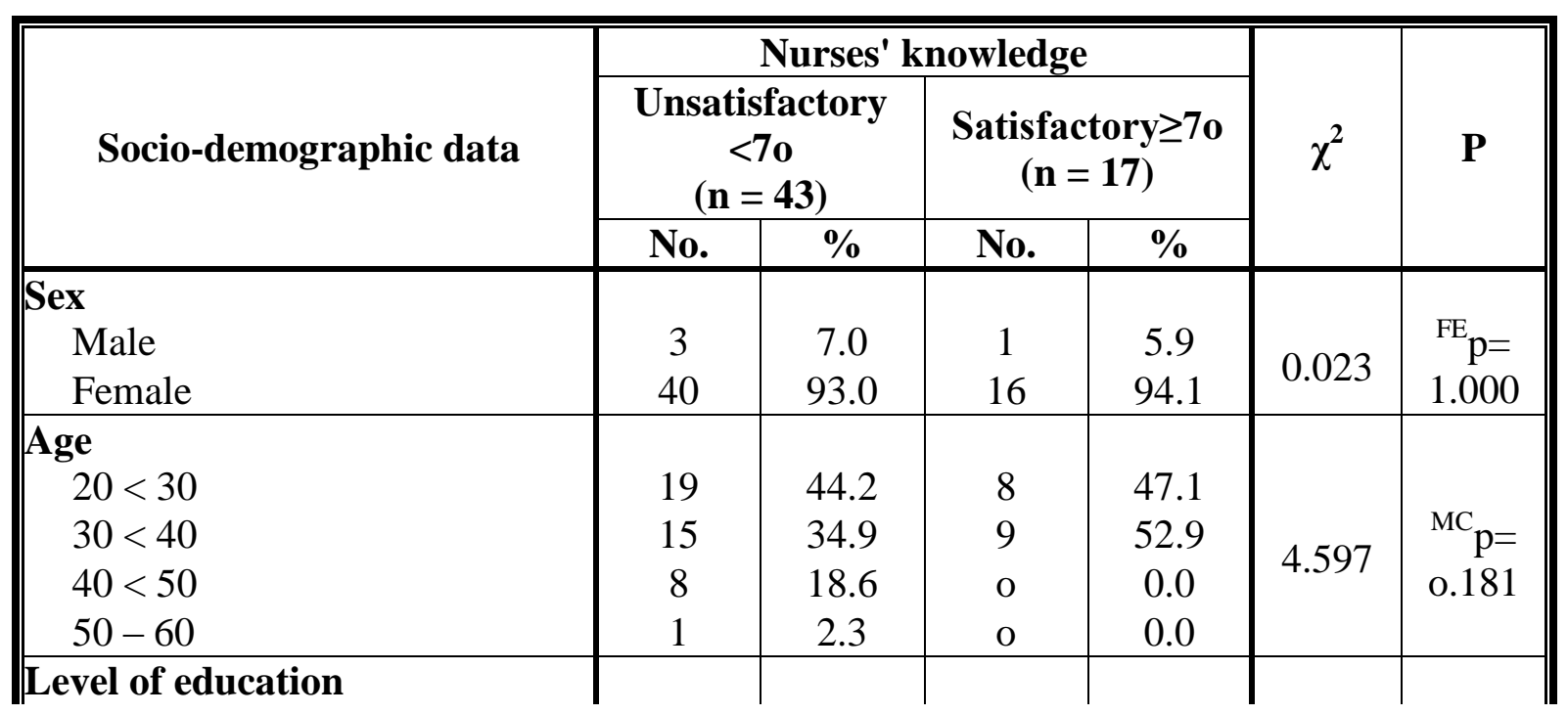




\begin{tabular}{||l|c|c|c|c|c|c||} 
Diploma three yea & 28 & 65.1 & 11 & 64.7 & & ${ }^{\mathrm{MC}} \mathrm{p}=$ \\
Nursing technician institute & 14 & 32.6 & 6 & 35.3 & 0.518 & 1.000 \\
Bachelor + Postgraduate studies & 1 & 2.3 & $\mathrm{o}$ & 0.0 & & \\
Marital status & 5 & 11.6 & 4 & 23.5 & & \\
$\quad$ Single & 38 & 88.4 & 12 & 70.6 & 3.961 & ${ }^{\mathrm{MC}} \mathrm{p}=$ \\
Married & 0 & 0.0 & 1 & 5.9 & & 0.138 \\
Divorced & & & & & & \\
& & & &
\end{tabular}

$\chi^{2}$ : Chi square test MC: Monte Carlo

FE: Fisher Exact

$\mathrm{p}: \mathrm{p}$ value for associated between different categories

*: Statistically significant at $\mathrm{p} \leq 0.05$

Table (3): Nurse's practice regarding postoperative discomfort among patients undergoing abdominal wall hernia repair according to their socio-demographic data $(\mathrm{n}=$ 60)

\begin{tabular}{|c|c|c|c|c|c|c|}
\hline \multirow{3}{*}{ Socio-demographic data } & \multicolumn{4}{|c|}{ Nurse's practice } & \multirow{3}{*}{$\chi^{2}$} & \multirow{3}{*}{$\mathbf{P}$} \\
\hline & \multicolumn{2}{|c|}{$\begin{array}{c}\text { Unsatisfactory }<70 \\
(\mathrm{n}=10)\end{array}$} & \multicolumn{2}{|c|}{$\begin{array}{c}\text { Satisfactory } \geq 70 \\
(n=50)\end{array}$} & & \\
\hline & No. & $\%$ & No. & $\%$ & & \\
\hline \multicolumn{7}{|l|}{$\overline{\operatorname{Sex}}$} \\
\hline Male & 2 & 20.0 & 2 & 4.0 & & $\mathrm{FE}_{\mathrm{p}}=$ \\
\hline Female & 8 & 80.0 & 48 & 96.0 & 3.429 & 0.126 \\
\hline \multicolumn{7}{|l|}{ Age } \\
\hline $20<30$ & 3 & 30.0 & 24 & 48.0 & & \\
\hline $30<40$ & 5 & 50.0 & 19 & 38.0 & & ${ }^{\mathrm{MC}} \mathrm{p}=$ \\
\hline $40<50$ & 1 & 10.0 & 7 & 14.0 & 4.606 & 0.211 \\
\hline $50-60$ & 1 & 10.0 & 0 & 0.0 & & \\
\hline
\end{tabular}




\begin{tabular}{|c|c|c|c|c|c|c|}
\hline \begin{tabular}{|l} 
Level of education \\
Diploma three year \\
Nursing technician institute \\
Bachelor + Postgraduate studies
\end{tabular} & $\begin{array}{l}7 \\
3 \\
0\end{array}$ & $\begin{array}{c}70.0 \\
30.0 \\
0.0\end{array}$ & $\begin{array}{c}32 \\
17 \\
1\end{array}$ & $\begin{array}{c}64.0 \\
34.0 \\
2.0\end{array}$ & 0.625 & $\begin{array}{c}{ }^{\mathrm{MC}} \mathrm{p}= \\
1.00\end{array}$ \\
\hline Marital status & & & & & & \\
\hline Single & 0 & 0.0 & 9 & 18.0 & & \\
\hline $\begin{array}{l}\text { Married } \\
\text { Divorced }\end{array}$ & $\begin{array}{l}9 \\
1\end{array}$ & $\begin{array}{l}90.0 \\
10.0\end{array}$ & $\begin{array}{c}41 \\
0\end{array}$ & $\begin{array}{c}82.0 \\
0.0\end{array}$ & 5.066 & $\begin{array}{r}\mathrm{p}= \\
0.086\end{array}$ \\
\hline
\end{tabular}

$\chi^{2}$ : Chi square test $\quad$ MC: Monte Carlo

FE: Fisher Exact

$\mathrm{p}: \mathrm{p}$ value for associated between different categories

*: Statistically significant at $\mathrm{p} \leq 0.05$

Table (4): Nurses' attitude regarding postoperative discomfort among patient undergoing abdominal wall hernia repair according socio-demographic data $(n=60)$

\begin{tabular}{|c|c|c|c|c|c|c|}
\hline \multirow{3}{*}{ Socio-demographic data } & \multicolumn{4}{|c|}{$\begin{array}{c}\text { Nurses' attitude toward postoperative } \\
\text { discomfort }\end{array}$} & \multirow{3}{*}{$\chi^{2}$} & \multirow{3}{*}{$\mathbf{P}$} \\
\hline & \multicolumn{2}{|c|}{$\begin{array}{c}\text { Negative }<70 \\
(n=40)\end{array}$} & \multicolumn{2}{|c|}{$\begin{array}{c}\text { Positive } \geq 70 \\
(n=20)\end{array}$} & & \\
\hline & No. & $\%$ & No. & $\%$ & & \\
\hline \multicolumn{7}{|l|}{ Sex } \\
\hline Male & 2 & 5.0 & 2 & 10.0 & \multirow{2}{*}{0.536} & ${ }^{\mathrm{FE}} \mathrm{p}=$ \\
\hline Female & 38 & 95.0 & 18 & 90.0 & & 0.595 \\
\hline Age & & & & & & \\
\hline
\end{tabular}




\begin{tabular}{||l|c|c|c|c|c|c||}
$20<30$ & 19 & 47.5 & 8 & 40.0 & & \\
$30<40$ & 16 & 40.0 & 8 & 40.0 & 1.744 & ${ }^{{ }^{2}} \mathrm{p}=$ \\
$40<50$ & 4 & 10.0 & 4 & 20.0 & & 0.732 \\
$50-60$ & 1 & 2.5 & 0 & 0.0 & & \\
\hline Level of education & 26 & 65.0 & 13 & 65.0 & & \\
Diploma three year & 13 & 32.5 & 7 & 35.0 & 0.559 & ${ }^{\mathrm{MC}_{\mathrm{p}}=1.000}$ \\
Nursing technician institute & 1 & 2.5 & 0 & 0.0 & & \\
Bachelor + Postgraduate studies & & & & & & \\
Marital status & 7 & 17.5 & 2 & 10.0 & & ${ }^{\mathrm{MC}_{\mathrm{p}}}$ \\
Single & 32 & 80.0 & 18 & 90.0 & 1.046 & 0.803 \\
Married & 1 & 2.5 & 0 & 0.0 & & \\
Divorced & &
\end{tabular}

$\chi^{2}$ : Chi square test

MC: Monte Carlo

FE: Fisher Exact

$\mathrm{p}$ : $\mathrm{p}$ value for associated between different categories

*: Statistically significant at $\mathrm{p} \leq 0.05$

Table (5): Correlation between total Nurses' knowledge, attitude and practice regarding postoperative discomfort among patient undergoing abdominal wall hernia repair.

\begin{tabular}{|l|c|c||}
\hline & $\mathbf{R}$ & $\mathbf{P}$ \\
\hline Knowledge VS Practice & -0.045 & 0.736 \\
\hline Knowledge VS attitude & 0.067 & 0.609 \\
\hline Practice VS altitude & -0.028 & 0.829 \\
\hline
\end{tabular}

r: Pearson coefficient $p$ value $\leq 0.05$

\section{DISCUSSION:}

Postoperative discomfort may be occurring by several factors, such as patients' disease, surgical procedures, anesthesia, and previous health states. Borgonovo's study showed that the need for research that can eventually help nurses' to become more knowledgeable with the factors that influence postoperative discomfort. With this knowledge in hand, they might be able to see the need for and develop nursing care to prevent or relieve postoperative discomfort (Borgonovo, Giussani, Grossi \& Maiorana, 2014).

According to study of (Abdalrahim, Majali \& Bergbom,, 2010; Zhang et al., 2008).Nurses play a vital role in relieving patients' suffering from postoperative discomfort. the nurses' 
work as mediator between the patient and health team members so the nurses' were being responsible for complete the whole process of post-operative. There is a great need to assess the knowledge, practice and attitude of nurses to improve care to patients. Therefore, this study was conducted to assess the nurses' existing of knowledge, skills and attitude regarding postoperative discomfort after hernia repair.

The present study revealed that, majority of the studied nurses were female, married and less than half of them their ages ranged from twenty to less than thirty years. This finding is in the same line with Abdalrahim et al., (2014) who mentioned that the mean age of their study nurses were 33.9 \pm 9.32 years and Inaba et al .,(2012) who stated that age sample was $28.9 \pm 6.32$ years, also regarding sex, Robleda et al., (2015) reported that the majority of their study sample was female. This is in the same line with the results of the present study which stated that about the majority of study nurses were female.

As regard level of education, the present study revealed that the majority of the studied nurses had diploma three years of nursing. This finding is in line with Mac Cartney\& Nelligan, (2015) who mentioned that the majority of nurses were in diploma three years, This is disagree with the result of Warraich et al.,(2013)who mentioned that the majority of the studied nurses had bachelor degree. This may be due to the sample of the present study is so smaller than that study that may not allow us to generalize the results and difference of setting also may affect the results of education.

In present study regarding attending training program related to postoperative discomfort demonstrate that eighteen of the studied nurses didn't attending training program, this highlights the need for giving importance for training of nurses in these setting. The results of the present study is supported with Glindvad \&Jorgensen,(2012) stated that about one third of nurses participating in their studies had undergone specialized training for management of postoperative discomfort Also, in same line study with (Mitchell,2013) established that only few nurses have attended a medical conference about discomfort management.

The them line studies by(Abdalrahim et al., 2010; Hall-Lord \& Larsson, 2014). Suggest that a need to improve the knowledge and attitudes of all health care professional. There is a need for the development of training programs and professional education trials. (Hall- 
Lord \& Larsson, 2014) showed that ongoing planned education is to improve and support discomfort management practices. It is essential that nurses' be taught about postoperative discomfort in their formal education and following registration to improve the management of postoperative discomfort. Education on techniques of reliving discomfort and accountability can also reduce misconceptions about discomfort (Young, Horton\& Davidhizar 2011)

Regarding nurses' knowledge, finding of the study indicated that more than two third of studied nurses had unsatisfactory total knowledge regarding post-operative discomfort of patients undergoing abdominal wall hernia repair, that may be reflect the lack in their scientific preparation and may be due to several factors as, lack of education, training program and most of nurses in this study had their nursing education at diploma level, the bachelor and master-prepared nurses had a mean score $1.7 \%$ from total. The level of nursing education was found to have a positive relationship with the level of knowledge.

In this agree with study of (Abdalrahim et al, 2014) the results of this study showed that majority of the studied nurses had unsatisfactory of total knowledge nurses then improved their knowledge and attitudes in postoperative discomfort management after the program was implemented. These findings are supported by (Maysoon et al 2015) who found that nurses had inadequate knowledge about post-operative discomfort management due to several factors might contribute lack of nurse's knowledge regarding post-operative discomfort management

Attitudes are unconscious motivations for actions and reaction in life that either be reinforced or altered by experience. Attitude change is influenced by the person's belief system, and people hold positive or negative beliefs about an object that determine their attitudes toward it (Bell, 2012). Yet, there are still many misconceptions concerning understanding postoperative discomfort and its management.

In the present study, statistical analysis has shown that more than two third of studied nurses had negative attitude. As in the same study by Ren, (2014) found that the nurses were inadequately prepared to care for patients with postoperative discomfort and consequently, held negative views about the disease and its treatment. This result disagreed with, mun et al., study (2014) also shown positive attitude among staff nurses toward patients suffering from postoperative discomfort. 
According the study of(Maysoon et al., 2015) showed that nurses' attitude originates from their culture and religious beliefs. Long-term plans should be developed to improve these beliefs, the fact that nurses continue to hold these beliefs can perhaps be explained by examining theories about health beliefs. A basic element in the shaping of beliefs is the acquisition of information. Thus education, and imparting knowledge, is an important element in development of beliefs. This indicates that educational strategies need to address both the affective and cognitive domains of discomfort management among nurses is to improve educational input, although the link between knowledge and the acquisition of skills needs considering.

The present study revealed that majority of the studied nurses' (83\%) had satisfactory of nurses' practice toward postoperative discomfort among patient undergoing abdominal wall hernia repair. The justification given by unsatisfactory nurses' practice for their weak skills in the above mentioned areas was high work load, under-staffing, and high patient volume, decrease of standardized nursing care procedures or no availability of manual book which contain all nursing procedures in discomfort after surgery, lack of facilities and equipment and decrease of knowledge is a barriers for needed for develop care of postoperative discomfort among patients undergoing abdominal wall hernia repair.

This is disagree with the result of Huang, Zheng\& Yuting (2015) study in the same setting, showed that nurses practice among patients undergoing inguinal hernia repair increase the patients' postoperative discomfort. Also these results disagree with (Wang, 2013) showed that the majority of nurse's have poor performance score regarding the studied postoperative discomfort among patients undergoing abdominal wall hernia repair.

As regarded to Relation between Nurses' knowledge regarding postoperative discomfort among patients undergoing abdominal wall hernia repair according to their sociodemographic data, there were not statistically significant relations between total nurses' knowledge and sex,age, level of education \& marital status . As regarded to Relation between Nurses' practice according to their socio-demographic data, there was not statistically significant between nurses' practice and sex,age, level of education \& marital status. In the same line there was not statistically significant deference between total nurses' attitude and sex,age, level of education \& marital status. 
This result similar to Robleda et al, (2015) mentioned that, not statistically significant relations between total nurses'knowledge,practice \& attitude acorrding to their scio demograghic data .

In present study, there were negative not statistically significant correlation between total nurses' knowledge, practice\& nurse attitude while there was positive statistically correlation between total nurses' attitude and knowledge regarding postoperative discomfort among patients undergoing abdominal wall hernia repair.

This result in the same line with Mcnamara, Harmon \& Saunders, (2012) study, the results of this study indicate not significant improvement of knowledge, attitude and practices among the nurses control of discomfort after a series of interventions. Focus on health workers education with new and innovative training methods is very effective. Should be target personnel's knowledge and attitude together to change their practice and improve their behavior.

\section{CONCLUSION:}

Most of studied nurses had unsatisfactory knowledge and satisfied practice regarding to post-operative discomfort after hernia repair. Moreover, more than two third of studied nurses had negative attitude. There are statically significant relation between total knowledge and total attitude. Meanwhile, there is no statically significant relation between total nurse's knowledge, practice and attitude regarding postoperative discomfort among patient undergoing abdominal wall hernia repair.

\section{RECOMMENDATIONS:}

\section{In the light of the study results, the following recommendations are proposed:}

- Provide nurses with continuous in service educational programs regarding postoperative discomfort among patients undergoing abdominal wall hernia repair to improve their knowledge, practice and attitude related to these patient.

○ Encourage and help nurses' to attend national and international conferences, workshops and training courses affiliated to ministry of health related to nursing performance regarding postoperative discomfort among patients undergoing abdominal wall hernia repair. 


\section{REFERENCES:}

Abdalrahim, M., Majali, S.,and Bergbom, I., (2010). Jordanian surgical nurses' experiences in caring for patients with postoperative discomfort Applied Nursing Research 23, 164-170.

Abdalrahim, M., Majali, S.,and Bergbom, I.,( 2014). Documentation of postoperative discomfort by nurses in the surgical wards. $10,73-81$.

Abu Elhamd,M(2015).Effect of Designed nursing Guidelines on Reducing post-operative discomfort Among patients undergoing abdominal surgery,Asut university; available at www.euc.edu.eg.Egyptian universities libraries, access at(4-1-2017).

Basavanthappa, B.T. (2015).Medical -Surgical Nursing, $3^{\text {rd }}$ ed., London.Jaypee Brothers Medical Publishers, p: 297-300

Bell, F., (2012). A review of the literature on the attitudes of nurses to discmfort management. Journal of Orthopedic Nursing 4, 64-7o.

Borgonovo, AE. Giussani, A. Grossi ,GB.and Maiorana, C.( 2014). Evaluation of postoperative discomfort after impacted mandibularthird molar surgery using three different types of flap. Quintessence Int.;45:319-330

Broekmans, S., Vanderschveren, S., Morlion, B., Kumar, A.,and Evers, G., (2014). Nurses' attitudes toward discomfort treatment with opioids: a survey in a Belgian university hospital. International Journal of Nursing Studies 41, 183-189.

Chintamani.(2016).Lewis Medical Surgical Nursing, 3ed.,Australia.Elsevier india,p;396400.

Fitzgibbons, R.J. (2016). Inguinal hernia. Schwartz principles of surgery. 8th Ed In: Charles Brunicardi, Dana K. Anderson, McGraw Hill.;1353-93.

Ferrell ,BR.\& McCaffery, M. (2014). Knowledge and Attitudes Survey Regarding discomfort.CityofHope.Availablefrom: http://prc.coh.org/Knowldege\%20\%20\&\% 20Attitude\%20Survey\%207-14\%20(1).pdf, accessed March 202016. 
Glindvad, J. \& Jorgensen, M. (2012) .Postoperative education and discomfort in patients with inguinal hernia. Journal of Advanced Nursing 57(6), 649-657 doi: $10.1111 / \mathrm{j} .1365-2648.2006 .04157 . x$

Hall-Lord, M., \&Larsson, B., (2014). Registered nurses' and student nurses' assessment of discomfort and distress related to specific patient and nurse characteristics. Nurse Education Today 26, 377e387

Huang,G. Zheng,H. and Yuting A.(2015). The Study on Perioperative Nursing for the Patients with Inguinal Hernia. JournalofNursing.4(2).Carr E (2017) Overcoming barriers to effective discomfort control. Prof Nurse 12(5): 412-6

Inaba, T.Okinaga, K.and Fukushima, R .( 2014). Chronic pain and discomfort after inguinal hernia repair. Surg Today;42:825-829.

Iqbal,M.Akhter,S.and Irfan,M.(2015)prevalence of hernia in relation to various risk factors in district Narowal,Pakistan.J ResearchGate.3(1):P.29.

Klopper, H., Andersson, H., Minkkinen, M., Ohlsoon, C., and Sjöström, B., (2o12). Strategies in assessing postoperative discomfort e A South African study. Intensive and Critical Care Nursing 22, 12-21.

Lewis, S., Dirksen, S., Heitkemper, M. and Bucher, L. (2016).Assessment and Management of Clinical Problems,Medical -Surgical Nursing, $8^{\text {th }}$ ed., Mosby Elsevier Inc.,section (5), p:578.

Linda, M. and Ignatavicius, D. (2o13).Patient-CenteredCollaborative Care, Medical Surgical Nursing, $7^{\text {th }}$ ed.,Elsevier Inc,p:663.

Linton,A.(2015).Introduction to Medical Surgical Nursing, $6^{\text {th }}$ ed.,Elsevier Health Sciences,p;272.

Maysoon S. Abdalrahim ,M, Sawsan A. Majali b , Margareta , and Ingegerd Bergbom.,(2015). The effect of postoperative discomfort management program on improving nurses' knowledge and attitudes toward discomfort. Nurse Education in Practice 11 (2011) 250-255

McNamara ,MC. Harmon ,D,.and Saunders, J(2012) . Effect of education on knowledge, skills and attitudes around pain. Br J Nurs ; 21 16:958-964.

Mitchell,M.(2o13).Anxiety management: a distinct nursing role in day surgery.Ambulatory Surgery ;8,119-127

Mun m, Suki S. K.(2014). Enhancing Knowledge and Attitudes in discomfort Management: A discomfort Management Education Program for Nursing Home Staff. discomfort Management Nursing;15 (1) : pp 2-11

Paice A., Toy C., and ShottS. (2014): Barriers to discomfort relief: Fear oftolerance and addiction. Journal of discomfort and Symptoms Management. 16(18); 1-9.

Ren, Z.(2014). Laparoscopic inguinal hernia repair perioperative nursing experience. Journal of Medical Information. ;27(6):333-334. 
Robleda,M. Sanchez ,(2015). Postoperative Discomfort After Abdominal Surgery: An Observational Study. Journal of Peri Anesthesia Nursing: 3o, (4): pp 272-279

Russell, R.C.G., Williams, N.S. and Bulstrode, C.J.K. (2017). Hernias, umbilicus and abdominal wall.Bailey \& Love's - Short practice of surgery, 25th Edition.London:Arnold.;968-9o.

Sultan, B., Qureshi, Z. and Malik, M.A. (2015). Frequency of external hernias inAyub Teaching Hospital Abbottabad. J Ayub Med CollAbbottabad;21(3):57-58.

Timby, B. and Smith, N. (2014): Introductory Medical Surgical Nursing, $11^{\text {th }}$ ed.,China. Lippincott Williams and Wilkins; P.p. 762-763.

Velanovich, V., Shaddik, P., Khaitan, L., Morton J, Maupin G. and Traverso, L.W. (2015). Analysis of the SAGES outcomes initiative groinhernia database. SurgEndos;2o:191-198.

Wang, X.(2013). Nursing experience from 51 cases of laparoscopic total extraperitoneal hernia repair. Journal of Qiqihar Medical College.;(17):2638 - 2639.

Warraich, R. Faisal, M.Rana, M. Shaheen, A. Gellrich, NC.and Rana, M.( 2013). Evaluation of post-operative discomfort following third molar surgery using submucosal dexamethasone - a randomized observer blind prospective study. Oral Surg Oral Med Oral Pathol Oral Radiol.;116:16-22.

Wells, N., Pasero, C. and McCaffery, M. (2015).Improving the quality of care through painassessment and management. In: Hughes RG, Ed. Patient Safety and Quality:An Evidence-Based Handbook for Nurses. Rockville, Maryland: Agency for Healthcare Research and Quality.

Wengström, Y., Geerling, J. and Rustøen, T. (2014).European Oncology Nursing Society [1o]breakthrough cancer pain guidelines. European Journal of Oncology Nursing.;18(2):127-31.

WHO (2016) Report of a WHO Study Group on Multiprofessional Education for Health Personnel: The Team Approach. WHO, Geneva.UKCC (2014) Fit for Practice. UKCC, London.

Williams,L.andHopper,P(2015):Understanding Medical Surgical Nursing, $10^{\text {th }}$ ed.,china.F.A.Davis;P.227.

Young, J., Horton, F., and Davidhizar,( 2011). Nursing attitudes and beliefs in pain assessment and management. Journal of Advanced Nursing 53, 412-421.

Zegerman A, Ezri T,and Weinbroum AA.( 2014). Post-operative discomfort (other than pain) - a neglected feature of postanesthesia patient care. J Clin Monit Comput.;22:279-284. 
Zhang, C., Hsu, L., Zou, B., Li, J., Wang, H.,and Huang, J.,( 2008). Effects of a pain education program on nurses' discomfort knowledge, attitudes and discomfort assessment practices in China. Journal of discomfort and Symptom Management $36(6), 616 \mathrm{e} 627$.

\section{اداء الممرضين تجاه عدم الارتياح بعد العملية الجراحية لاي المرضي الخاضعين لاصلاح فتق جدار البطن}

\section{الخلاصة}

يعد علاج عدم الارتياح بعد العملية الجر احية جزءا أساسيًا للرعاية الجيدة ، رعاية المريض في حالة عدم الارتباح

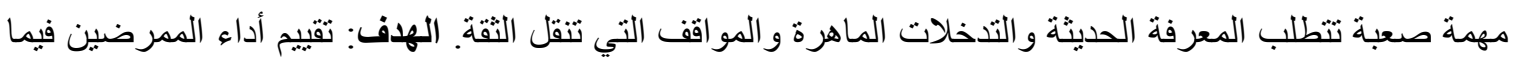
يتعلق بعدم الارتياح بعد العملية الجر احية بين المرضى الذين يخضعون لإصلاح فتق جدار البطن. تم استخدام تصميم بحثي وصفي. الإعداد: أجريت الدراسة الجراحية في مدينة بورسعيد (مستشفى الزهور ومستشفى بورسعيد العام)

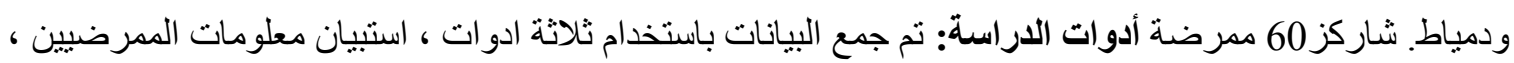
وقائمة الملاحظة لممارسة الممرضيين وسلوك الممرضيين تجاه عدم الارتباح بعد العملية الجر احية. النتيجة: أثشارت

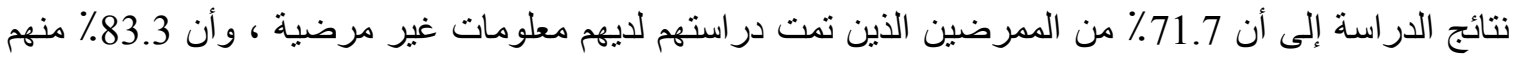

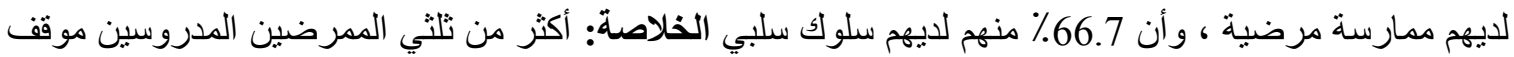
سلبي. التوصيات: هنالك حاجة واضحة لإجراء برامج تعليمية وتدريبية في الخدمة لتحسين معرفة الممرضة

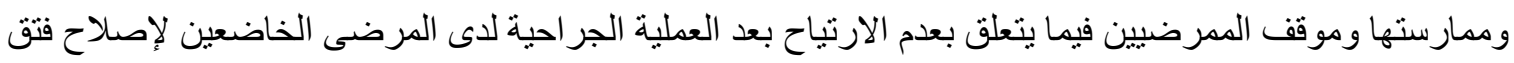

